\title{
An application of ARIMA model for predicting total health expenditure in China from 1978-2022
}

\author{
Ang Zheng1, Quan Fang², \\ Yalan Zhu' ${ }^{2}$, Chunling \\ Jiang $^{3}$, Feng Jin ${ }^{1}$, Xin \\ Wang ${ }^{2}$
${ }^{1}$ Department of Breast Surgery, the First Affiliated Hospital of China Medical University, Shenyang, Liaoning Province, China
${ }^{2}$ College of the Humanities and Social Sciences, China Medical University, Shenyang, Liaoning Province, China
${ }^{3}$ College of Basic Medical Science, China Medical University, Shenyang, Liaoning Province, China

\begin{abstract}
Background China's health financing system has changed from the government-led mode under the planned economy to the diversified mode under the market economy. Equity in health financing has been a national health priority. This study aimed to predict changes in total health expenditure (THE), government health expenditure (GHE), social health expenditure (SHE) and out-ofpocket health expenditure (OOP) in China from 2018 to 2022, and to provide a theoretical basis for health policy adjustment.
\end{abstract}

Methods Based on health expenditure date of time series from 1978-2017, R3.5.1 software was used to construct the Autoregressive Integrated Moving Average (ARIMA) model.

Results The model of THE, GHE, SHE and OOP are ARIMA (3.3.0), ARIMA (1.3.1), ARIMA (2.4.0), ARIMA (2.2.2). According to the simulation results, in 2022, China's THE is expected to reach 8473.00 billion Yuan, and the constituent ratios in GHE, SHE and OOP will be $25.49 \%, 51.25 \%$ and $23.26 \%$, respectively. The proportion of THE to GDP will continuously increase from 2018-2022 at a reasonable pace, while THE itself will increase rapidly.

Conclusions China should take effective measures to control the excessive growth of THE, keep decreasing the OOP percentage, and improve the efficiency and fairness of the use of health funds.

\section{Correspondence to:}

Xin Wang, Professor, Ph.D. China Medical University No.77 Puhe Road

Shenyang North New Area Shenyang Liaoning Province 110122 China (PRC)

wxinsmile@qq.com
The total health expenditure (THE) is the total amount of money consumed by the whole society within a certain period for medical and health services, such as disease control, medical treatment, rehabilitation, and health promotion, which occurred as a form of currency in a country or region [1,2]. It contains government health expenditure (GHE), social health expenditure (SHE) and out-of-pocket health expenditure (OOP) [3]. THE objectively reflects the relationship between national macro-health policies and economic development, which provides information for the government in making and adjusting related health policies. Equity in health financing is not only related to the amount of THE, but also the structure among the three components [4]. Increasing the proportion of OOP may cause people to forgo care and become poor [5-7]. In 2010, OOP pushed an estimated 97 million people ( $1.4 \%$ of the world's population) below the US\$ 1.90 per day extreme poverty line [8]. Increasing the proportion of GHE to SHE would more equally distribute health costs and reduce poverty rates [9].

China is considered to have one of the highest cash payment rates in Asia and irrational health financing structures is the main problem [10]. In 1998, 44.8\% of urban citizens and $79.1 \%$ of rural residents in China were not covered by any so- 
cial health security system and they paid for health care by OOP [11]. According to a report by the World Health Organization (WHO) in 2000, in terms of equity in health financing, China was listed as fourth from bottom among 192 member states, which was far from expectations [12]. Therefore, to solve this problem, a New Cooperative Medical Scheme (NCMS) and a new governmental public health service funding had been adopted in 2003 and 2009, respectively [13,14]. Since the reform of the medical and health system, $90 \%$ of China's population has been covered by medical insurance [15].

Although China's THE increased by 476 times from 1978 to 2017, the inflation and continued population growth may lead to the per capita THE lower. There was a slight downward trend in GHE and THE, while OOP increased slightly before 2003. After that, this phenomenon began to reverse. Besides, the Proportion of THE in GDP had increased year by year, accounting for 6.36\% in 2017. Meanwhile, the proportion of GHE in THE fluctuated in recent years after a continuous increase, and OOP appeared a sluggish decline [16]. This makes health policy formulation and implementation more difficult.

Scientific analysis and prediction of THE and its composition can provide recommendations for evaluating and formulating health financing policies, health reform, and development strategies. Several previous studies focused on the change of THE, while the change trend and forecast of the financing source of THE was rarely reported [17-19]. Wang 's paper used Autoregressive integrated moving average (ARIMA) model to analyze and predict THE and its composition in China from 1978 to 2016 [20]. But it had two major problems. One was limited predictive power in this model, which made it more difficult to make policy and easier to provide wrong information. For example, GHE as a proportion of THE has decreased by $1.11 \%$, while OOP has risen by $0.02 \%$ in 2017 , which is contrary to Wang's predictions [20]. Another was unreliable THE caused by errors accumulation. THE was calculated by the predicted GHE, SHE, OOP, but not by ARIMA model. To avoid the error above and get precise information, this study analyzed the changing trend of THE and the changing characteristics of financing sources from the reform and opening up to 2017, and to predict the change trend of China's total THE from 2018-2022 using the ARIMA model time series method, from three sources: GHE, THE, and OOP.

\section{METHODS}

\section{Data source}

The paper cited the THE, CHE, SHE, OOP in China from 1978 to 2017, from the China Statistical Yearbook [16].

\section{Model construction}

The ARIMA model has the advantages of simplicity and stability. THE is driven by several factors and the ARIMA model is considered the most appropriate model under existing conditions [21]. (ARIMA) (p, d, q) model is an extension of autoregressive (AR), moving average (MA), and ARMA model [22]. p is the order of AR; $d$ is the degree of difference and $q$ is the order of MA. ARIMA model is developed with four synergistic steps including time series stationary, model identification, parameter estimation and diagnostic checking [23]. First, THE, CHE, SHE, OOP were plotted against time to detect and correct for non-stationarity of the time series. Stationarity was judged by the Augmented Dickey-Fuller (ADF) test. Probability values less than 0.05 were considered statistically significant, indicating that the sequence was stationary. Second, identified AR and MA were needed by calculating the autocorrelation (ACF) and partial autocorrelation (PACF) functions. Next, models of different orders were fitted and compared with Akaike information criteria (AIC) to evaluate the improvement of fitting [24]. Auto Arima function package in R software can quickly find the most suitable model. Last, temporal autocorrelation was confirmed to have been no longer present in model residuals using the Ljung-Box test $(P>0.05)$ [25]. R statistical software version 3.5.1 (R Foundation,Vienna, Austria) was used to carry out the analyses.

\section{Model prediction tests}

THE, SHE, GHE and OOP from 2013 to 2022 were predicted according to ARIMA models. The validity of the model was evaluated by comparing the difference between the predicted value and the real value in 2013-2017 and the MAPE (Mean absolute percent error) in 2017-2022. 


\section{RESULTS}

\section{Current THE in China}

Since 1978, both China's GDP and THE have been increasing year by year. The ratio of THE to GDP increased from $3.00 \%$ in 1978 to $6.36 \%$ in 2017. GHE, SHE, OOP also increased year by year. Among them, GHE increased from $32.16 \%$ in 1978 to $38.69 \%$ in 1986. After that, GHE decreased continuously. SHE had a similar trend to GHE. OOP has dropped below 30\% in recent years from a high of $59.97 \%$ in 2001 (Table 1).

Table 1. China's GDP and total health financing composition*

\begin{tabular}{|c|c|c|c|c|c|c|c|c|c|}
\hline \multirow[b]{2}{*}{ Years } & \multirow[b]{2}{*}{$\begin{array}{l}\text { GDP } \\
\text { (BแLION YuAM) }\end{array}$} & \multicolumn{2}{|c|}{ THE } & \multicolumn{2}{|c|}{ GHE } & \multicolumn{2}{|c|}{ SHE } & \multicolumn{2}{|c|}{ OOP } \\
\hline & & $\begin{array}{c}\text { Absolute } \\
\text { number } \\
\text { (billion Yuan) }\end{array}$ & $\begin{array}{l}\text { Proportion } \\
\text { in GDP } \\
(\%)\end{array}$ & $\begin{array}{c}\text { Absolute } \\
\text { number } \\
\text { (billion Yuan) }\end{array}$ & $\begin{array}{c}\text { Proportion } \\
\text { in THE } \\
(\%)\end{array}$ & $\begin{array}{c}\text { Absolute } \\
\text { number } \\
\text { (billion Yuan) }\end{array}$ & $\begin{array}{l}\text { Proportion } \\
\text { in THE } \\
(\%)\end{array}$ & $\begin{array}{c}\text { Absolute } \\
\text { number } \\
\text { (billion Yuan) }\end{array}$ & $\begin{array}{c}\text { Proportion } \\
\text { in THE } \\
(\%)\end{array}$ \\
\hline 1978 & 367.87 & 11.02 & 3.00 & 3.54 & 32.16 & 5.23 & 47.41 & 2.25 & 20.43 \\
\hline 1979 & 410.05 & 12.62 & 3.08 & 4.06 & 32.21 & 5.99 & 47.45 & 2.57 & 20.34 \\
\hline 1980 & 458.76 & 14.32 & 3.12 & 5.19 & 36.24 & 6.10 & 42.57 & 3.04 & 21.19 \\
\hline 1981 & 493.58 & 16.01 & 3.24 & 5.97 & 37.27 & 6.24 & 38.99 & 3.80 & 23.74 \\
\hline 1982 & 537.34 & 17.75 & 3.30 & 6.90 & 38.86 & 7.01 & 39.49 & 3.84 & 21.65 \\
\hline 1983 & 602.09 & 20.74 & 3.44 & 7.76 & 37.43 & 6.46 & 31.12 & 6.52 & 31.45 \\
\hline 1984 & 727.85 & 24.21 & 3.33 & 8.96 & 36.96 & 7.36 & 30.41 & 7.90 & 32.64 \\
\hline 1985 & 909.89 & 27.90 & 3.07 & 10.77 & 38.58 & 9.20 & 32.96 & 7.94 & 28.46 \\
\hline 1986 & 1037.62 & 31.59 & 3.04 & 12.22 & 38.69 & 11.04 & 34.93 & 8.33 & 26.37 \\
\hline 1987 & 1217.46 & 37.96 & 3.12 & 12.73 & 33.53 & 13.73 & 36.16 & 11.51 & 30.31 \\
\hline 1988 & 1518.04 & 48.80 & 3.21 & 14.54 & 29.79 & 19.00 & 38.93 & 15.27 & 31.28 \\
\hline 1989 & 1717.97 & 61.55 & 3.58 & 16.78 & 27.27 & 23.78 & 38.64 & 20.98 & 34.09 \\
\hline 1990 & 1887.29 & 74.74 & 3.96 & 18.73 & 25.06 & 29.31 & 39.22 & 26.70 & 35.73 \\
\hline 1991 & 2200.56 & 89.35 & 4.06 & 20.41 & 22.84 & 35.44 & 39.67 & 33.50 & 37.50 \\
\hline 1992 & 2719.45 & 109.69 & 4.03 & 22.86 & 20.84 & 43.16 & 39.34 & 43.67 & 39.81 \\
\hline 1993 & 3567.32 & 137.78 & 3.86 & 27.21 & 19.75 & 52.48 & 38.09 & 58.10 & 42.17 \\
\hline 1994 & 4863.75 & 176.12 & 3.62 & 34.23 & 19.43 & 64.49 & 36.62 & 77.41 & 43.95 \\
\hline 1995 & 6133.99 & 215.51 & 3.51 & 38.73 & 17.97 & 76.78 & 35.63 & 100.00 & 46.40 \\
\hline 1996 & 7181.36 & 270.94 & 3.77 & 46.16 & 17.04 & 87.57 & 32.32 & 137.22 & 50.64 \\
\hline 1997 & 7971.50 & 319.67 & 4.01 & 52.36 & 16.38 & 98.41 & 30.78 & 168.91 & 52.84 \\
\hline 1998 & 8519.55 & 367.87 & 4.32 & 59.01 & 16.04 & 107.10 & 29.11 & 201.76 & 54.85 \\
\hline 1999 & 9056.44 & 404.75 & 4.47 & 64.10 & 15.84 & 114.60 & 28.31 & 226.06 & 55.85 \\
\hline 2000 & 10028.01 & 458.66 & 4.57 & 70.95 & 15.47 & 117.19 & 25.55 & 270.62 & 58.98 \\
\hline 2001 & 11086.31 & 502.59 & 4.53 & 80.06 & 15.93 & 121.14 & 24.10 & 301.39 & 59.97 \\
\hline 2002 & 12171.74 & 579.00 & 4.76 & 90.85 & 15.69 & 153.94 & 26.59 & 334.21 & 57.72 \\
\hline 2003 & 13742.20 & 658.41 & 4.79 & 111.69 & 16.96 & 178.85 & 27.16 & 367.87 & 55.87 \\
\hline 2004 & 16184.02 & 759.03 & 4.69 & 129.36 & 17.04 & 222.54 & 29.32 & 407.14 & 53.64 \\
\hline 2005 & 18731.89 & 865.99 & 4.62 & 155.25 & 17.93 & 258.64 & 29.87 & 452.10 & 52.21 \\
\hline 2006 & 21943.85 & 984.33 & 4.49 & 177.89 & 18.07 & 321.09 & 32.62 & 485.36 & 49.31 \\
\hline 2007 & 27023.23 & 1157.40 & 4.28 & 258.16 & 22.31 & 389.37 & 33.64 & 509.87 & 44.05 \\
\hline 2008 & 31951.55 & 1453.54 & 4.55 & 359.39 & 24.73 & 506.56 & 34.85 & 587.59 & 40.42 \\
\hline 2009 & 34908.14 & 1754.19 & 5.03 & 481.63 & 27.46 & 615.45 & 35.08 & 657.12 & 37.46 \\
\hline 2010 & 41303.03 & 1998.04 & 4.84 & 573.25 & 28.69 & 719.66 & 36.02 & 705.13 & 35.29 \\
\hline 2011 & 48930.06 & 2434.59 & 4.98 & 746.42 & 30.66 & 841.65 & 34.57 & 846.53 & 34.77 \\
\hline 2012 & 54036.74 & 2811.90 & 5.20 & 843.20 & 29.99 & 1003.07 & 35.67 & 965.63 & 34.34 \\
\hline 2013 & 59524.44 & 3166.90 & 5.32 & 954.58 & 30.14 & 1139.38 & 35.98 & 1072.93 & 33.88 \\
\hline 2014 & 64397.40 & 3531.24 & 5.48 & 1057.92 & 29.96 & 1343.78 & 38.05 & 1129.54 & 31.99 \\
\hline 2015 & 68905.21 & 4097.46 & 5.95 & 1247.53 & 30.45 & 1650.67 & 40.29 & 1199.27 & 29.27 \\
\hline 2016 & 74358.55 & 4634.49 & 6.23 & 1391.03 & 30.01 & 1909.67 & 41.21 & 1333.79 & 28.78 \\
\hline 2017 & 82712.20 & 5259.83 & 6.36 & 1520.59 & 28.90 & 2225.88 & 42.30 & 1513.36 & 28.80 \\
\hline
\end{tabular}

GHE - government health expenditure, THE - total health expenditure, OOP - out-of-pocket health expenditure, GDP - gross domestic product; SHE - social health expenditure

*Source: Authors' analysis and China Statistical Yearbook (1979-2018). 


\section{Model estimation and checking}

THE, GHE, SHE and OOP are non-stationary time series, which need to be differentiated. Under the condition of $\mathrm{ADF}<0.05, \mathrm{~d}_{\mathrm{THE}}=3, \mathrm{~d}_{\mathrm{GHE}}=3, \mathrm{~d}_{\mathrm{SHE}}=4, \mathrm{~d}_{\mathrm{THE}}=2$, Draw the corresponding ACF and PACF. The possible model is determined according to ACF, PACF and the Auto Arima function package in R software. If $P$ value of residual LB test is greater than 0.05, the minimum value of AIC means that the model is optimal. Finally, the model of THE, GHE, SHE and OOP are ARIMA (3.3.0), ARIMA (1.3.1), ARIMA (2.4.0), ARIMA (2.2.2).

\section{Forecasting results}

The predicted values were calculated according to the respective ARIMA model. Compared with real values, the mean relative error of GHE, THE, SHE and OOP in 2013-2017 were 1.36\%, 2.76\%, 2.33\%, and $2.01 \%$, respectively (Table 2). In 2018-2022, the predicted values of THE, GHE, SHE and OOP all keep rising, and an absolute value of increase keeps increasing. In 2022, THE, GHE, SHE and OOP were 9447.90 billion Yuan, 2260.50 billion Yuan, 4544.31 billion Yuan, and 2062.42 billion Yuan, respectively. GHE and OOP's share of THE continued to decrease, from $28.02 \%$ to $25.49 \%$ and $27.97 \%$ to $23.26 \%$, respectively, whereas SHE increased from $44.01 \%$ to $51.25 \%$. The lowest MAPE was THE (2.57\%), followed by SHE (3.73\%), GHE (4.20\%), and OOP (6.07\%). The specific situation of forecast every year was presented in Table 3.

\section{DISCUSSION}

China's health financing system has changed from the government-led mode under the planned economy to the diversified mode under the market economy [26]. From 1978 to 2017, China had achieved remarkable results in total health financing and financing structure, but now there is still space for more optimized and efficient improvement. At present, China's health care costs have grown much faster than economic growth by far [27]. According to the requirements of "Healthy China 2020" Strategic Planning, the proportion of THE in GDP will reach 6.5\% to 7.0\% [28]. So we will focus on the optimization of financing structure. Irrational health financing structures directly lead to a severe disease economic burden on the population and even harm the socio-economic situation in the short or long term [29].

The mean average error of the predicted value compared with the real value from 2013 to 2017 in the Arima model adopted in this study was less than 3\%, and the highest MAPE value was only $6.07 \%$ for the

Table 2. Comparison of predicted and actual values from 2013 to 2017

\begin{tabular}{|c|c|c|c|c|c|c|}
\hline Category & Years & Predictive value & Real value & Absolute error & Relative erroB (\%) & MeAN ReLATIVE ERROR (\%) \\
\hline \multirow{5}{*}{ THE } & 2013 & 3212.36 & 3166.90 & 45.46 & 1.44 & \multirow{5}{*}{1.36} \\
\hline & 2014 & 3548.25 & 3531.24 & 17.01 & 0.48 & \\
\hline & 2015 & 4005.31 & 4097.46 & 92.16 & 2.25 & \\
\hline & 2016 & 4570.95 & 4634.49 & 63.54 & 1.37 & \\
\hline & 2017 & 5194.56 & 5259.83 & 65.27 & 1.24 & \\
\hline \multirow{5}{*}{ GHE } & 2013 & 983.43 & 954.58 & 28.85 & 3.02 & \multirow{5}{*}{2.72} \\
\hline & 2014 & 1064.27 & 1057.92 & 6.35 & 0.60 & \\
\hline & 2015 & 1170.56 & 1247.53 & 76.97 & 6.17 & \\
\hline & 2016 & 1403.60 & 1391.03 & 12.57 & 0.90 & \\
\hline & 2017 & 1564.47 & 1520.59 & 43.88 & 2.89 & \\
\hline \multirow{5}{*}{ SHE } & 2013 & 1175.87 & 1139.38 & 36.49 & 3.20 & \multirow{5}{*}{2.33} \\
\hline & 2014 & 1313.36 & 1343.78 & 30.42 & 2.26 & \\
\hline & 2015 & 1573.01 & 1650.67 & 77.67 & 4.71 & \\
\hline & 2016 & 1925.85 & 1909.67 & 16.18 & 0.85 & \\
\hline & 2017 & 2211.28 & 2225.88 & 14.60 & 0.66 & \\
\hline \multirow{5}{*}{ OOP } & 2013 & 1058.06 & 1072.93 & 14.87 & 1.39 & \multirow{5}{*}{2.01} \\
\hline & 2014 & 1170.71 & 1129.54 & 41.17 & 3.65 & \\
\hline & 2015 & 1216.32 & 1199.27 & 17.05 & 1.42 & \\
\hline & 2016 & 1313.32 & 1333.79 & 20.47 & 1.53 & \\
\hline & 2017 & 1481.81 & 1513.36 & 31.55 & 2.08 & \\
\hline
\end{tabular}

GHE - government health expenditure, THE - total health expenditure, OOP - out-of-pocket health expenditure; SHE - social health expenditure 
Table 3. The forecast of China's THE and financing composition from 2018 to 2022

\begin{tabular}{|c|c|c|c|c|c|}
\hline Category & Years & Predictive value & $95 \%$ CI & Proportion In THE (\%) & MAPE (\%) \\
\hline \multirow{5}{*}{ THE } & 2018 & 5942.01 & 5822.97-6061.05 & - & \multirow{5}{*}{2.57} \\
\hline & 2019 & 6756.98 & $6513.70-7000.26$ & - & \\
\hline & 2020 & 7562.75 & 7154.31-7971.19 & - & \\
\hline & 2021 & 8473.00 & 7843.70-9102.30 & - & \\
\hline & 2022 & 9447.90 & $8506.60-10389.21$ & - & \\
\hline \multirow{5}{*}{ GHE } & 2018 & 1662.91 & $1595.73-1730.09$ & 28.02 & \multirow{5}{*}{4.20} \\
\hline & 2019 & 1805.07 & $1680.88-1929.27$ & 27.43 & \\
\hline & 2020 & 1953.33 & $1751.72-2154.94$ & 26.91 & \\
\hline & 2021 & 2104.65 & $1815.35-2393.95$ & 26.24 & \\
\hline & 2022 & 2260.50 & $1870.55-2650.45$ & 25.49 & \\
\hline \multirow{5}{*}{ SHE } & 2018 & 2611.44 & $2554.52-2668.35$ & 44.01 & \multirow{5}{*}{3.73} \\
\hline & 2019 & 3013.57 & $2908.65-3118.49$ & 45.80 & \\
\hline & 2020 & 3464.06 & $3308.89-3619.24$ & 47.72 & \\
\hline & 2021 & 3980.31 & $3750.33-4210.28$ & 49.63 & \\
\hline & 2022 & 4544.31 & $4220.75-4867.87$ & 51.25 & \\
\hline \multirow{5}{*}{ OOP } & 2018 & 1659.64 & $1601.17-1718.12$ & 27.97 & \multirow{5}{*}{6.07} \\
\hline & 2019 & 1761.22 & $1651.45-1871.00$ & 26.77 & \\
\hline & 2020 & 1841.49 & $1688.68-1994.31$ & 25.37 & \\
\hline & 2021 & 1935.55 & $1743.32-2127.79$ & 24.13 & \\
\hline & 2022 & 2062.42 & $1824.00-2300.84$ & 23.26 & \\
\hline
\end{tabular}

GHE - government health expenditure, THE - total health expenditure, OOP - out-of-pocket health expenditure, SHE - social health expenditure, MAPE - mean absolute percentage error

predicted results from 2018 to 2022 , while the others were less than $5.00 \%$. Because the fitting degree is better than other studies [19], the prediction results are greater value for reference.

China's THE is increasing exponentially [30]. The reasons may be the increasing financial input to medical institutions, the policy of full coverage of medical insurance, the acceleration of the aging trend of China's population and the increasing demand of the people for a better life. In 2022, the proportion of THE in GDP will be approximately $8.2 \%$ (the average growth rate, as measured by GDP growth in 2017, maybe slightly lower). This indicates that the total funding of financing for health in China is continuously improving, and the health industry is constantly advancing. In the United States, THE accounted for $17.1 \%$ of GDP in 2014. However, if China keeps the trend of rapid rise, it may push up the fiscal deficit and debt level and increase the risk of a national debt crisis, which may also lead to increased government taxes. High taxes are bound to curb the potential of economic growth [31], which is bound to adversely affect the sustainability of health financing. That's not going to happen in 2022, because we're going to step up our efficiency priorities to be better able to deal with it when it does happen.

\section{GHE for THE}

Nationwide, although GHE has been increasing continuously since 2015, the proportion of GHE has been decreasing due to the rapid growth of SHE. GHE is predicted to fall to $25.49 \%$ in 2022 , decreased by $3.41 \%$. Compared with developed countries, the proportion of GHE was far less than the United States (43.2\% in 2013) and Japan, Canada and Italy (all above 70\%) [32,33]. Under the premise of certain GHE, to achieve higher output effect and maximize benefits, more attention should be paid to the rational allocation and use efficiency of funds. Besides, the guiding role of the government in the field of health should continue to be emphasized. We should improve the construction of the medical security system, expand the coverage of serious disease insurance and increase its reimbursement rate, and include safe and effective medicines in the national list of medicines for basic medical insurance, so as to reduce the burden of medical expenses on individuals.

\section{SHE for THE}

In 2001, the ratio of SHE was only 24.1\% in China, which was the lowest in all years. In the 15 years before 2017, the ratio of SHE increased year by year except in 2011, which might be related to universal health care. The population coverage by health insurance was from around $29.7 \%$ in 2003 to over $90 \%$ at the end of 2010 [27]. In the forecast results, SHE is the fastest growing and the largest increment. The 
proportion of SHE in THE will be $51.25 \%$. SHE mainly consists of two parts: the basic medical insurance fund and the social capital input paid by the units and individuals, which are included in the coverage of urban employees' basic medical insurance [34]. In the case of limited GHE, SHE should be increased to alleviate the problem of "expensive medical treatment". We can increase the contribution of enterprises and individuals, encourage social capital to set up hospitals, especially traditional Chinese medicine. At the same time, it is necessary to increase the social health input, give play to the advantages of "simplicity, convenience, testing and integrity" of traditional Chinese medicine, meet people's diversified demands for medical services. All of these can be used to effectively control the unreasonable growth of health expenditure [35].

\section{OOP for THE}

In developing countries, such as China, OOP forms a greater proportion of the sources of health care financing [36]. Although the proportion of OOP has been decreasing worldwide, the decline in China is more pronounced [8]. Unlike GHE, the proportion of OOP in THE keeps going down, reaching to 23.26\% in 2022, which is in line with the test requirements of the world health organization in the Asia-pacific health financing strategy (2010-2015) in 2009. The proportion of the total personal cash health expenditure will not exceed 30\% to 40\% [3]. But WHO illustrated that when individual cash health spending falls to $15 \%-20 \%$, the chance of economic hardship and poverty drops to negligible levels [37].

In China, high-quality medical resources are mostly concentrated in the 3A (Class Three/Grade A) hospitals. Drug zero markup policy implementation lead to increase the hospital checking cost, medical service cost prices and the cost of the entire health system, so the actual OOP of patients remain very high [38]. Besides implementing policies, the key is to transfer the burden of individual medical treatment. Therefore, it is crucial to ensure the source of social funds.

The international significance of this study can be discussed in the following aspects: First, this study used the ARIMA model time series method, from three sources: GHE, THE, and OOP. This innovative model can be applied in other countries. Second, although this study was analyzed based on data from China, it can be used by other countries for comparison. Third, other countries can adjust their own policies according to the policy in China and the suggestions in this paper. High health expenditure and irrational health financing structures is an issue facing the whole world, and the rise of which not only relies on different medical system respectively, but also correlates with the common aspects. The changing trends of THE and financing sources in China is an integrated part of health accounting internationalization study. The prediction of China's total THE provide reference for the study around the world in the future.

This study has some limitations. First, ignoring inflation will lead to absolute value estimation less accurate, so this study adopts ratio. Second, the model's estimates are based on data from the past, and it will still be tested given the uncertainties of the future. Third, the premise of the forecast is that the existing policies and statistical caliber do not change significantly. Otherwise, the predicted results are meaningless.

\section{CONCLUSIONS}

From 2018-2022, THE will increase rapidly. The proportion of GHE, OOP in THE will decline, and SHE will grow fastest. The change of health financing structure in China will slow down. In the next step, China should take effective measures to control the rapid growth of the total health expenditure, increase social health input continuously, improve the efficiency and fairness of the government's health funds, and focus on the transformation of patient-centered treatment and prevention. 


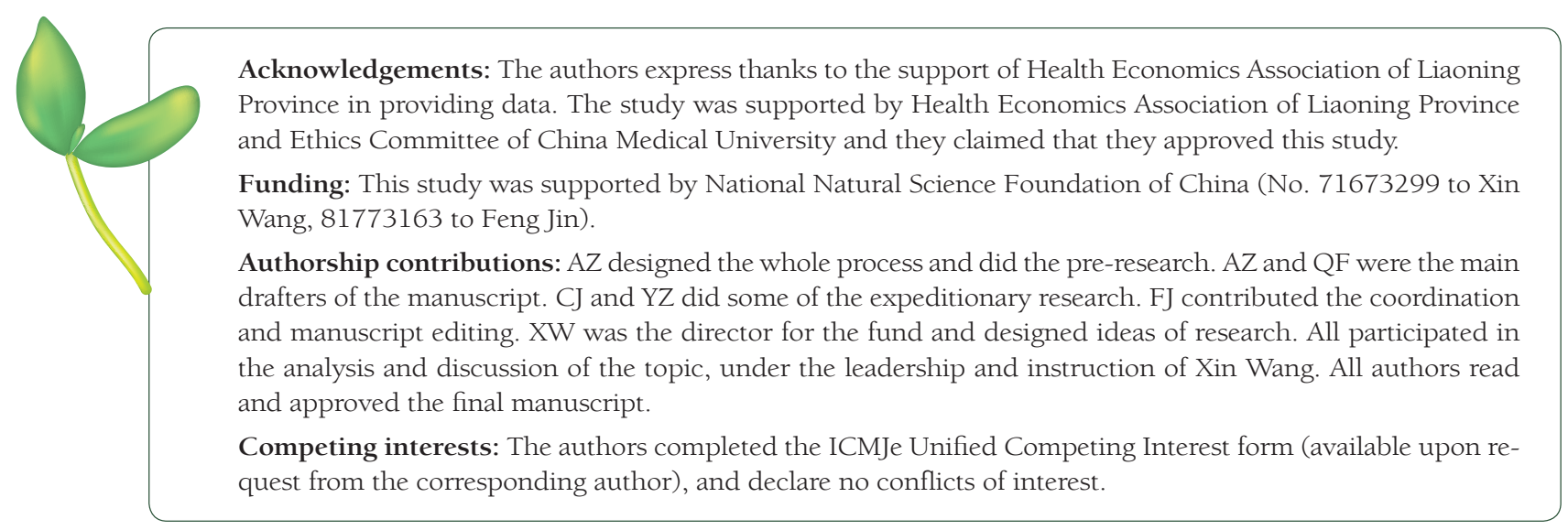

1 Long Q, Xu L, Bekedam H, Tang S. Changes in health expenditures in China in 2000s: Has the health system reform improved affordability. Int J Equity Health. 2013;12:40. Medline:23764104 doi:10.1186/1475-9276-12-40

2 Tsounis N, Vlachvei A. Advances in panel data analysis in applied economic research. Springer Proceedings in Business and Economics; 2018.

3 World Health Organization. Health Financing Strategy for the Asia Pacific Region (2010-2015). Geneva: World Health Organization; 2009.

4 Wang X, Sun YL, Mu X, Guan L, Li JJ. How to improve the equity of health financial sources? - Simulation and analysis of total health expenditure of one Chinese province on system dynamics. Int J Equity Health. 2015;14:73. Medline:26306500 doi:10.1186/s12939-015-0203-x

5 Bremer P. Forgone care and financial burden due to out-of-pocket payments within the German health care system. Health Econ Rev. 2014;4:36. Medline:26208936 doi:10.1186/s13561-014-0036-0

6 Onah MN, Govender V. Out-of-pocket payments, health care access and utilisation in south-eastern Nigeria: A gender perspective. PLoS One. 2014;9:e93887. Medline:24728103 doi:10.1371/journal.pone.0093887

7 Grande D, Barg FK, Johnson S, Cannuscio CC. Life disruptions for midlife and older adults with high out-of-pocket health expenditures. Ann Fam Med. 2013;11:37-42. Medline:23319504 doi:10.1370/afm.1444

8 Wagstaff A, Flores G, Smitz MF, Hsu J, Chepynoga K, Eozenou P. Progress on impoverishing health spending in 122 countries: a retrospective observational study. Lancet Glob Health. 2018;6:e180-92. Medline:29248366 doi:10.1016/ S2214-109X(17)30486-2

9 Kim TJ, Vonneilich N, Lüdeck D, Knesebeck O. Income, financial barriers to health care and public health expenditure: A multilevel analysis of 28 countries. Soc Sci Med. 2017;176:158-65. Medline:28153752 doi:10.1016/j. socscimed.2017.01.044

10 Yip W, Hsiao W. The Chinese health system at a crossroads. Health Aff (Millwood). 2008;27:460-8. Medline:18332503 doi:10.1377/hlthaff.27.2.460

11 Center for Health Statistics and Information. MOH. An analysis report of National Health Services Survey in 1998. Beijing: Peking Union Medical College Press; 1999.

12 World Health Organization. World health report 2000. Beijing: Public Health Report Press; 2000.

13 Wagstaff A, Lindelow M, Gao J, Xu L, Qian JC. Extending health insurance to the rural population: An impact evaluation of China's new cooperative medical scheme. J Health Econ. 2009;28:1-19. Medline:19058865 doi:10.1016/j.jhealeco.2008.10.007

14 Liu Y, Yuan Z, Liu Y, Jayasinghe UW, Harris MF. Changing community health service delivery in economically less-developed rural areas in China: impact on service use and satisfaction. BMJ Open. 2014;4:e004148. Medline:24583760 doi:10.1136/bmjopen-2013-004148

15 Meng Q, Xu L, Zhang Y, Qian J, Cai M, Xin Y, et al. Trends in access to health services and financial protection in China between 2003 and 2011: a cross-sectional study. Lancet. 2012;379:805-14. Medline:22386034 doi:10.1016/S01406736(12)60278-5

16 National Bureau of Statistics of the People's Republic of China. China Statistical Yearbook. Beijing: China statistics press; 2018.

17 Zheng JF, Yin WQ, Yu QQ, Chen ZM, Jia HY, Zhu LL, et al. The trend forecast of total health expenditure during the 13th five-year plan period based on ARIMA model. Chinese Journal of Health Statistics. 2016;33:823-5.

18 Dai MF, Meng Q. China's total health expenditure forecast during the 13th five-year plan period. Chinese Journal of Health Statistics. 2017;34:263-5.

19 Chen PJ, Li DS. Predictive analysis of Chinese Total Health Expenditure Base on ARIMA Model. Med Soc. 2016;29:18-20.

20 Wang GL, Zhang YQ. Forecast and analysis of total health expenditure trend and composition based on ARIMA model in China. Chinese Journal of Health Statistics. 2019;36:123-7. 
21 Anwar MY, Lewnard JA, Parikh S, Pitzer VE. Time series analysis of malaria in Afghanistan: using ARIMA models to predict future trends in incidence. Malar J. 2016;15:566. Medline:27876041 doi:10.1186/s12936-016-1602-1

22 Rojas I. Pomares, Héctor. Time Series Analysis and Forecasting.Contributions to Statistics; 2016.

23 Box G. Box and Jenkins: Time Series Analysis, Forecasting and Control. A Very British Affair. Palgrave Macmillan UK; 2013.

24 Bozdogan H. Model selection and Akaike's Information Criterion (AIC): The General Theory and its analytical extensions. Psychometrika. 1987;52:345-70. doi:10.1007/BF02294361

25 Huitema BE, Mckean JW. An improved portmanteau test for autocorrelated errors in interrupted time-series regression models. Behav Res Methods. 2007;39:343-9. Medline:17958144 doi:10.3758/BF03193002

26 Chen LH, Xiao Y. Analysis on financing level and structure of total health expenditure in China. The western BBS. 2010;6:72-77.

27 Tang S, Tao J, Bekedam H. Controlling cost escalation of healthcare: Making Universal Health Coverage sustainable in China. BMC Public Health. 2012;12 Suppl 1:S8. Medline:22992484 doi:10.1186/1471-2458-12-S1-S8

28 Editorial committee of healthy China 2020 strategy research report. Healthy China 2020 strategy research report. Beijing: People's Medical Publishing House, 2012-8.

29 Wagstaff A, Yip W, Lindelow M, Hsiao WC. China's health system and its reform: a review of recent studies. Health Econ. 2009;18 Suppl 2:S7-23. Medline:19551753 doi:10.1002/hec.1518

30 Ma GF, Li X, Chou LJ, Li XY, Sheng HQ, Ma AN, et al. Prediction of the growth of total health expenses in China's medical institutions and analysis of the development stage. Chin J Publ Health. 2018;34:1-4.

$31 \mathrm{Ma}$ J, Zhu ML, Xiao ZM. Research on China's national assets and liabilities. Beijing Social Sciences Literature Publishing House. 2012.

32 Deng F, Lu JH, Gao JM, An HY. Comparative analysis of medical resources and health costs between China and developed countries. Chinese Health Economy. 2014;2:91-3.

33 World Health Organization. Global Health Expenditure Database. 2016. Available: http://apps.who.int/nha/database/Select/Indicators/en. Accessed: 10 January 2018.

34 China Insurance Statistics Report in 2013. China Insurance Regulatory Commission, 2014. Available: http://www.circ. gov.cn/web/site0/tab5257/info3 901864.htm. Accessed: 10 January 2018.

35 Hui W, Wu HZ. To accelerate the improvement of the basic strategy research of social capital medical management in China. Chinese Hospital Management. 2014;34:4-5.

36 Qin X, Luo HY, Feng J, Li YN, Wei B, Feng QM. Equity in health financing of Guangxi after China's universal health coverage: evidence based on health expenditure comparison in rural Guangxi Zhuang autonomous region from 2009 to 2013. Int J Equity Health. 2017;16:174. Medline:28962656 doi:10.1186/s12939-017-0669-9

37 World Health Report 2010: health systems financing the path to universal coverage. Geneva. World Health Rep. 2010.

38 Kraipornsak P. Factors determining health expenditure in the Asian and the OECD countries. Economics World. 2017;5:407-17. doi:10.17265/2328-7144/2017.05.003 